\title{
ESTUDO COMPARATIVO ENTRE O PROCESSO DE ROSQUEAMENTO INTERNO COM MACHO DE CORTE E O ROSQUEAMENTO INTERNO COM MACHO LAMINADOR EM FERRO FUNDIDO NODULAR AUSTEMPERADO: UMA ABORDAGEM DAS GRANDEZAS FÍSICAS
}

\author{
Claudinei Haag ${ }^{1}$
}

Marcos Roberto Morachik Amancio²

\begin{abstract}
RESUMO
Este trabalho tem por objetivo comparar o desempenho de machos de corte e machos laminadores no processo de rosqueamento interno em ferro fundido nodular austemperado (ADI), tendo em vista as grandezas físicas envolvidas. A maioria das peças fabricadas na indústria possui roscas internas utilizadas como elemento de fixação e transmissão de movimento. Todavia, muitas dessas peças são produzidas com materiais de usinagem relativamente difícil, como é o caso do ADI. A obtenção de estabilidade e confiabilidade no processo é de suma importância, quando se trata de rosqueamento interno, pois pode comprometer todo o fluxo anterior, se porventura falhar. Um levantamento do estado da arte evidenciou a necessidade de se caracterizar e mensurar os fenômenos relacionados às variáveis do processo, bem como as características físicas da ferramenta e da peça de modo a prever, da melhor forma possível, a sua aplicabilidade. O estudo aponta para uma superioridade teórica do rosqueamento por laminação, em detrimento ao processo similar por corte, em ADI. Tal afirmação se baseia nas melhores características dessas ferramentas para este processo, como a maior resistência ao torque, por exemplo. Em contrapartida, evidenciou-se a criticidade desta aplicação em função da elevada dureza e abrasão características do material, além da necessidade de uma boa fixação e estabilidade do conjunto máquina-ferramenta. Todavia, há de se realizar ensaios que possibilitem a visualização dos parâmetros estudados e a caracterização do melhor processo, tendo em vista a numerosa quantidade de variáveis envolvidas.
\end{abstract}

Palavras-chave: Rosqueamento. ADI. Laminação.

\footnotetext{
${ }^{1}$ Especialista, e-mail: claudinei.haaag@sc.senai.br

2Tecnólogo, e-mail: marcos.morachik@gmail.com
} 


\section{INTRODUÇÃO}

Há algum tempo, e de forma mais latente depois da Primeira Revolução Industrial, a utilização de materiais oriundos de fundição passou a ser altamente explorada de forma a desenvolver produtos que agreguem características mecânicas previsíveis e, atualmente, design que privilegie a economia de espaço e energia. A utilização em larga escala de ferros fundidos se justifica pelo baixo custo e boa confiabilidade no processo de fundição, sendo utilizados para a grande maioria das peças na indústria automotiva (CALLISTER JUNIOR, 2002; GUESSER, 2009) Um bom exemplo disso é classe dos ferros fundidos nodulares austemperados (Austempered Ductile Iron - ADI). O ADI possui dentre suas variadas classes valores que balanceiam boa resistência mecânica, ductilidade e dureza, além de peso reduzido transformando-se em um material em grande ascensão em peças de engenharia (GUESSER, 2009). Em contrapartida, devido à dureza relativamente elevada e a possível formação de martensita revenida durante a usinagem, ele é geralmente usinado antes do tratamento térmico de austêmpera elevando os custos com logística e pós-processo (BARBOSA, 2009).

Além disso, processos de fabricação com elevada complexidade geométrica, onde haverá um ciclo de reprocesso, prejudicam a qualidade de trabalho exigida. O rosqueamento é um bom exemplo desta problemática. O rosqueamento é utilizado na indústria de transformação de variadas formas, como em elementos de fixação (como roscas para parafusos diversos) e elementos de transmissão (como os fusos de máquinas ferramenta), por exemplo. É importante salientar que por ser, na maioria dos casos, dependente de pré-acabamento, acaba sendo executado posteriormente aos demais processos de usinagem. Desta forma, qualquer erro que porventura aconteça, pode causar a inutilidade da peça, ocasionando também a perda dos processos anteriores, sendo, portanto imprescindível a sua correta configuração (REIS et al., 2003. FROMENTIN, 2004; VELDHUIS; DOSBAEVA e BENGA, 2007).

Dentre as várias formas de se obter uma superfície com roscas, o processo de rosqueamento interno com macho de corte é apontado por muitos autores como o mais utilizado (REIS et al., 2003; PEREIRA, 2010; DA MOTA, 2006; CAO, SUTHERLAND, 2002). Este tipo de rosqueamento é complexo, pois envolve ferramentas com geometrias singulares e limitação de movimentos da máquina ferramenta exigindo alta precisão e rigidez nas suas etapas.

Os machos de corte normais possuem limitações quanto à vida da ferramenta, principalmente quando as roscas são executadas em furos "cegos", pois a presença de cavaco acaba se tornando um agravante, levando a construção de ferramentas com canais adaptados para escoamento do fluxo de cavaco e entrada de fluido refrigerante, em detrimento da resistência mecânica da ferramenta (VELDHUIS; DOSBAEVA; BENGA, 2007; IVANOV; KIROV, 1996). Desta forma, a pesquisa das formas de rosqueamento que tenham melhor aproveitamento produtivo se faz relevante. 


\section{DESENVOLVIMENTO}

\subsection{Ferro fundido nodular austemperado (ADI).}

Segundo Keough (2000), fatores como custo de fabricação e eficiência energética fazem do ferro fundido nodular austemperado (ADI) uma boa opção no desenvolvimento de novos produtos, acompanhando a tendência de redução dos impactos ambientais no processo produtivo. A razão para tal afirmação está ligada ao menor impacto da fabricação e a menor densidade deste material se comparado aos aços, por exemplo. Nessa classe os níveis de resistência ao desgaste são elevados, tornando grande a aplicabilidade em casos onde esse fator é de grande importância, como em peças utilizadas em máquinas agrícolas, por exemplo.

Dentre outras características deste material, a que talvez seja a de maior relevância é a capacidade de agregar diversas propriedades mecânicas de forma equilibrada devido a presença de ausferrita na composição da matriz. A tabela 1 apresenta as classes conforme norma EN e os valores típicos das propriedades mecânicas diversas.

Tabela 1: Propriedades mecânicas e físicas dos ferros fundidos nodulares austemperados segundo as classes da norma EN 1: Média de 3 ensaios, valores individuais maiores ou iguais a $9 \mathrm{~J}$.

\begin{tabular}{|c|c|c|c|c|}
\hline $\begin{array}{l}\text { Classe de ferro fundido nodular } \\
\text { austemperado }\end{array}$ & GJS-800-8 & GJS-1000-5 & GJS-1200-2 & GJS-1400-1 \\
\hline \multicolumn{5}{|l|}{ Valores mínimos } \\
\hline Limite de resistência - LR (MPa) & 800 & 1000 & 1200 & 1400 \\
\hline Limite de escoamento - LE 0,2 (MPa) & 500 & 700 & 850 & 1100 \\
\hline Alongamento & 8 & 5 & 2 & 1 \\
\hline Resistência ao impacto entalhado (J) & $10(1)$ & - & - & - \\
\hline
\end{tabular}

Fonte: Adaptado de Guesser (2009)

A classe GJS800-8, por exemplo, tem valores de resistência a tração mínima de 800MPa e, em contrapartida,um alongamento considerável de no mínimo $8 \%$ além de elevada dureza. A usinagem de peças da família dos nodulares austemperados traz grandes solicitações às ferramentas de corte devido ao aumento de propriedades mecânicas 
como dureza e limite de resistência (GUESSER, 2009; BARBOSA, 2009). O gráfico 1 compara a usinabilidade deste material com outros materiais largamente utilizados na industria de transformação.

Gráfico 1: Usinabilidade relativa de um ferro fundido nodular austemperado

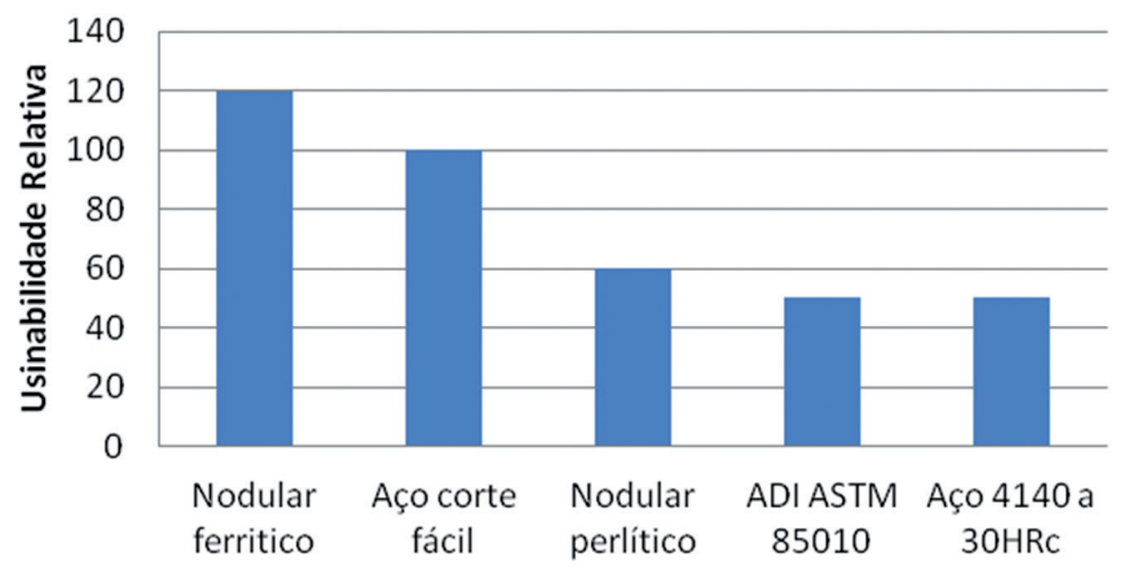

Fonte: Adaptado de Guesser (2009)

O gráfico permite visualizar que para a classe ASTM 85010 a usinabilidade decai a níveis similares a de um aço 4140 endurecido à $30 \mathrm{HRc}$ e, em contrapartida possuem níveis cerca de duas vezes inferiores à usinabilidade de ferro fundido nodular ferrítico. Além da elevada dureza, a possibilidade de formação de martensita revenida durante o processo de usinagem contribui para que a usinabilidade decaia consideravelmente. Essa possibilidade de formação de martensita advém da presença de austenita retida de alto carbono, oriunda do tratamento térmico de austêmpera (SEKER, HASIRCI, 2006). A micrografia abaixo (figura 1) revela a presença de austenita na matriz junto aos nódulos de grafita.

Figura 1: Micrografia de ferro fundido nodular austemperado com matriz ausferrítica - composta por austenita de alto carbono

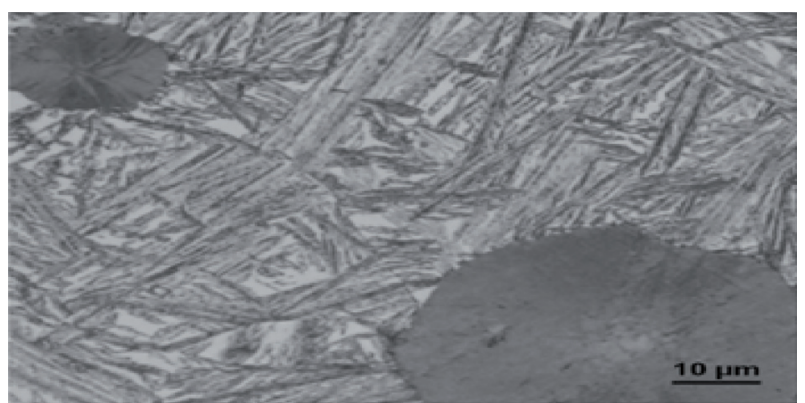

Fonte: Guesser (2009) 
A figura 1 ilustra a presença dos nódulos de grafita em uma matriz composta por ferrita acicular (porções escuras) e austenita de alto carbono (porções claras). A austenita é estável mecânica e termicamente devido ao tratamento térmico, porém, pode se transformar em martensita durante a deformação plástica no momento da formação do cavaco levando a o aumento da resistência nesta etapa (KLOCKE et al., 2007). Na usinagem deste material são típicos grandes níveis de desgaste de cratera, desgaste abrasivo, esforço de corte e até mesmo adesão em ferramentas de metal duro, devido à presença de ausferrita (KLOCKE et al., 2007). A dificuldade ao usinar o ADI leva, muitas vezes, à execução da operação de usinagem antes do processo de austêmpera, aumentando, desta forma os custos de fabricação (GUESSER, 2009).

\subsection{Grandezas físicas no processo de rosqueamento por corte}

O rosqueamento interno com macho de corte é uma das operações de usinagem mais complexas. Esta afirmação é confirmada no trabalho de grande parte dos pesquisadores que buscam entender melhor este processo (DA MOTA, 2006; PEREIRA, 2010; REIS et al., 2003). A complexidade da geometria das ferramentas; as dificuldades técnicas inerentes à máquina-ferramenta; a dificuldade na expulsão do cavaco e da penetração do fluido refrigerante são alguns dos principais problemas levantados por estes pesquisadores. Outro grande problema é a dificuldade para alcançar níveis satisfatórios de velocidade de corte. A figura 2 ilustra os movimentos resultantes deste processo. Devido à alta complexidade e velocidade dos movimentos não é raro que ocorram erros de sincronização, por parte da máquina ferramenta, principalmente nos modelos mais antigos e quando há grandes níveis de rotação, em ferramentas de pequeno diâmetro por exemplo.

Figura 2: Movimentos necessários para a execução do processo de rosqueamento interno com macho

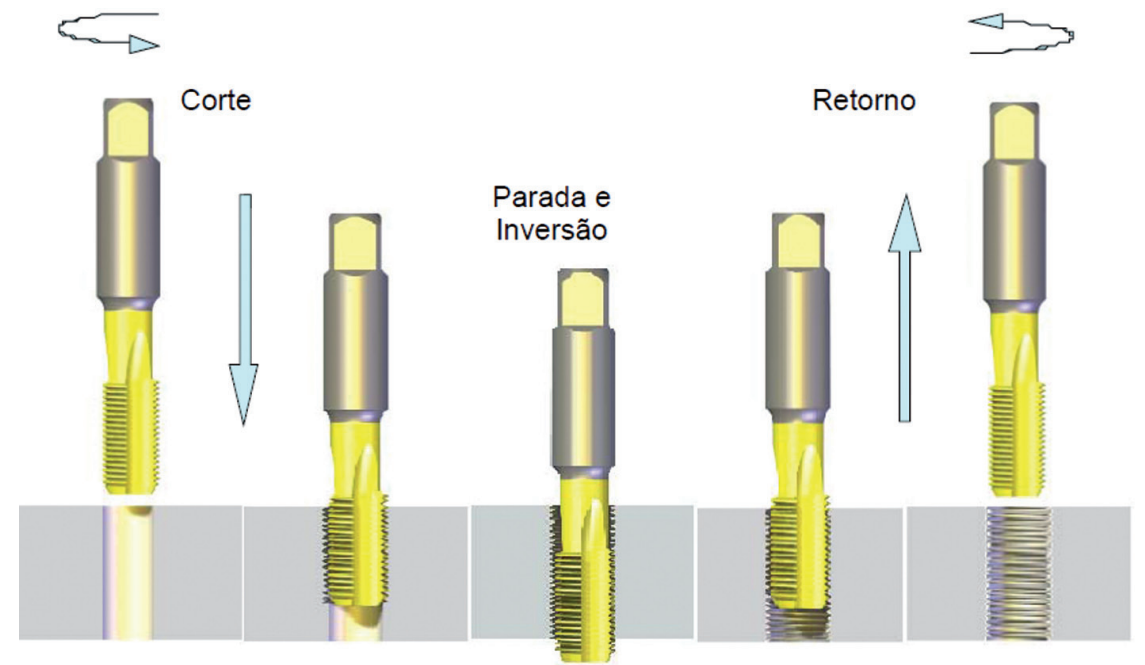

Fonte: Da Mota (2006) 
Como já observado, os erros de sincronismo, geralmente estão ligados a altas velocidades de corte, uma vez que a máquina, muitas vezes não é capaz de manter a harmonia dos movimentos de rotação e avanço de entrada, parada no fundo da peça e inversão de rotação para saída (PEREIRA, 2010; REIS et al., 2003; AHN et al., 2003) ilustrados na figura 2. Há ainda a grande dificuldade da penetração de fluido lubrificante na interface cavaco ferramenta devido ao enclausuramento da ferramenta e do curto intervalo de tempo entre cada operação. Além disso, há a dificuldade de expulsão de cavaco em furos "cegos". Tais fatores fazem com que as ferramentas para este tipo específico de aplicação possuam canais para o escoamento de cavaco para fora da cavidade, perdendo, desta forma grande parte de sua resistência mecânica, estas alterações na geometria acarretam, por sua vez, grandes diferenças nos valores de torque (LORENZ, 1980). Desta forma é imprescindível o conhecimento dos valores de torque e esforço axial tendo em vista as direções que as forças atuam e a influencia nos parâmetros e na dinâmica do processo. 0 gráfico 2 ilustra as etapas do processo de rosqueamento por corte em função do torque.

Gráfico 2: Valores de torque para rosqueamento interno com macho de corte com as principais etapas de rosqueamento

\section{Torque}

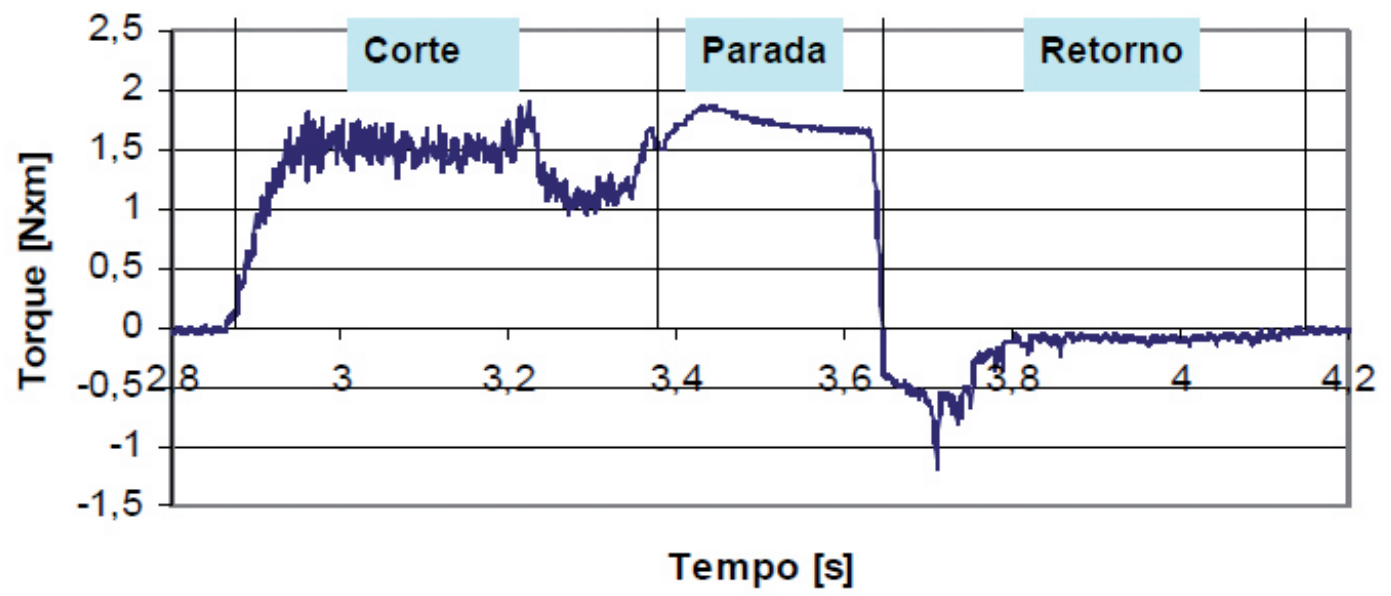

Fonte: Pereira (2010)

Como ilustra o gráfico 2 os valores de torque tendem ao máximo quando o macho está iniciando o processo de corte com os primeiros filetes e se mantêm na fase em que os filetes da fase cilíndrica do macho estão em ação (DA MOTA, 2009). No movimento de parada ao final do furo, o sinal de torque se mantém linear até que se torne negativo no retorno da ferramenta. Mesmo no movimento de saída da ferramenta, onde não há corte, algumas circunstâncias podem aumentar consideravelmente o torque na ferramenta, 
como a presença de cavaco e partículas do revestimento ou a falta de sincronismo da máquina, por exemplo, ocasionando maiores níveis de atrito entre as arestas de corte e o filete da rosca (PEREIRA, 2010).

Alguns fatores podem afetar substancialmente os valores de torque. Com a evolução dos níveis de desgaste, os valores de torque tendem a aumentar devido à elevação do atrito e a perda do revestimento por abrasão. O gráfico 3 mostra os níveis de torque em função da evolução do desgaste da ferramenta.

Gráfico 3: Comparação dos sinais de torque com a evolução da vida da ferramenta

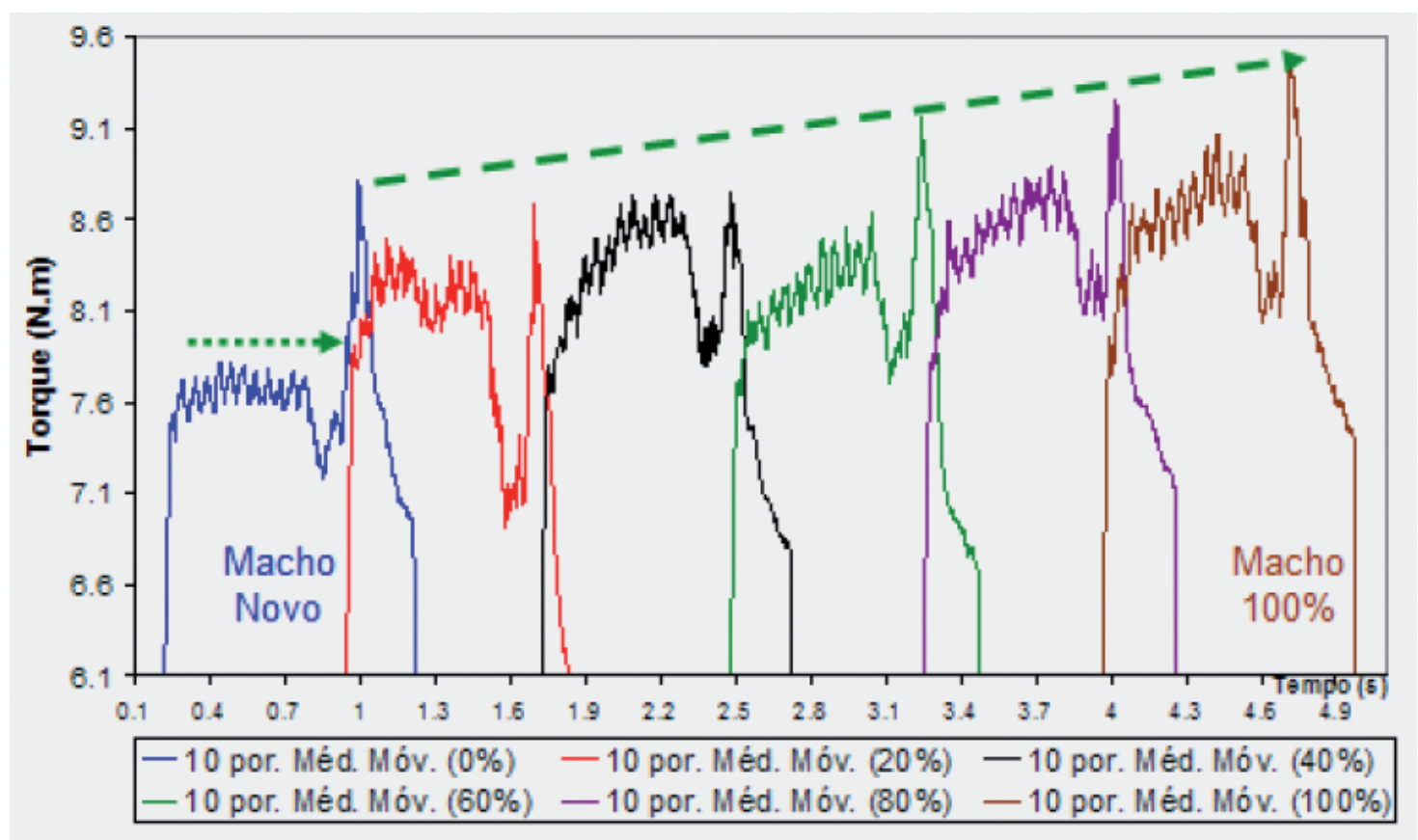

Fonte: Da Mota (2006)

É possível observar no gráfico 3 que à medida que os níveis de desgaste se estendem, os valores de torque aumentam, principalmente na entrada do macho na peça devido aos maiores níveis de esforço de corte nesta região (DA MOTA, 2006). Outro fator importante na análise do torque no rosqueamento é o comprimento da rosca produzida. Para não exceder os esforços gerados pelo atrito, o valor comprimento máximo da rosca é previamente especificado pelo fabricante e geralmente é dado em função do diâmetro nominal da rosca. Pereira (2010), em seus ensaios mostrou a influência do comprimento de corte nos valores de torque e verificou que com o seu aumento há um acréscimo progressivo do torque como pode ser observado no gráfico 4 . 
Gráfico 4: Efeito do comprimento de corte nos valores de torque

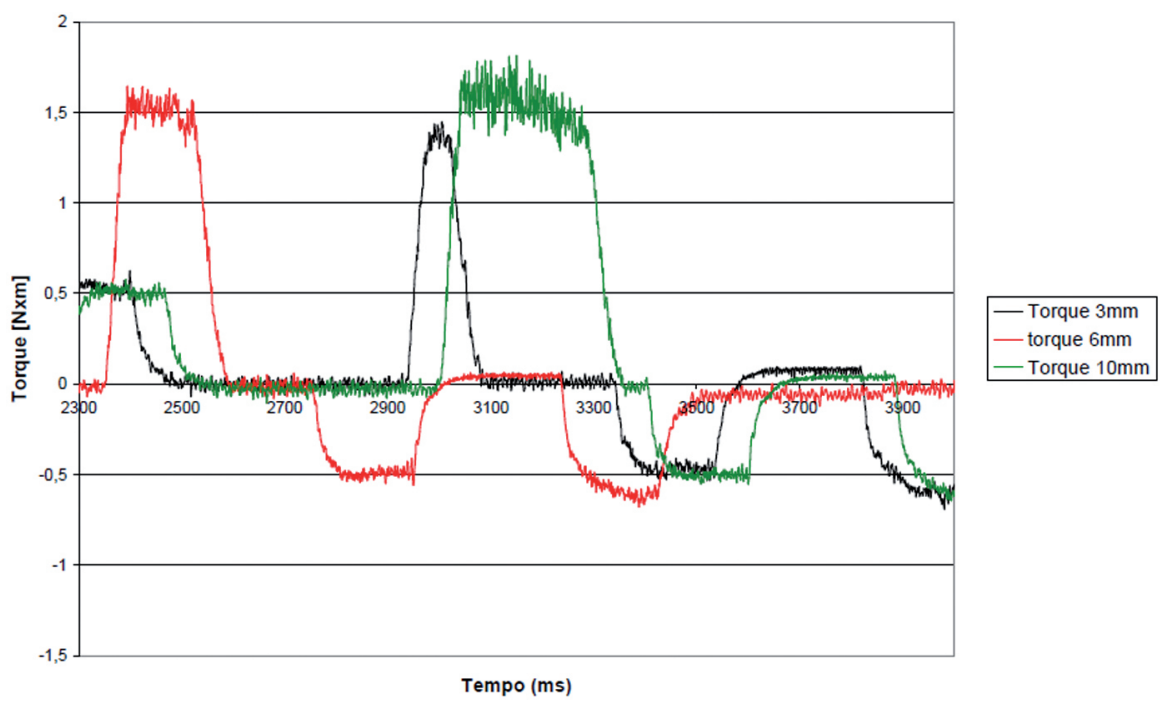

Fonte: Pereira (2010)

Observa-se no gráfico 4, que à medida que a profundidade de corte aumenta, os níveis de torque de formação também aumentam. Além disso, há a presença de picos de torque na fase onde a rosca já está formada devido à presença de cavaco entre os filetes. Como evidenciam Cao e Sutherland (2002) ao investigar um modelo de previsão de forças no processo de rosqueamento, o aprisionamento de cavaco pode ser fator que aumenta em até cinco vezes os valores de torque se comparados ao torque de formação e atrito. Tal fator pode comprometer grandemente o processo levando à quebra da ferramenta.

A falta de sincronismo, que pode ser agravada pelo aumento da velocidade de corte, é um dos fatores que possuem relativa influência nos valores de torque. A presença e influência dos erros de sincronismo foi avaliada por Ahn et al. (2003) como pode ser visto no gráfico 5 . O autor utilizou a ferramenta MMC103 do fabricante Siemens para monitoramento dos servos motores para avaliação dos erros de sincronismo. 
Gráfico 5: Comparação dos sinais de torque para os diferentes passos programados

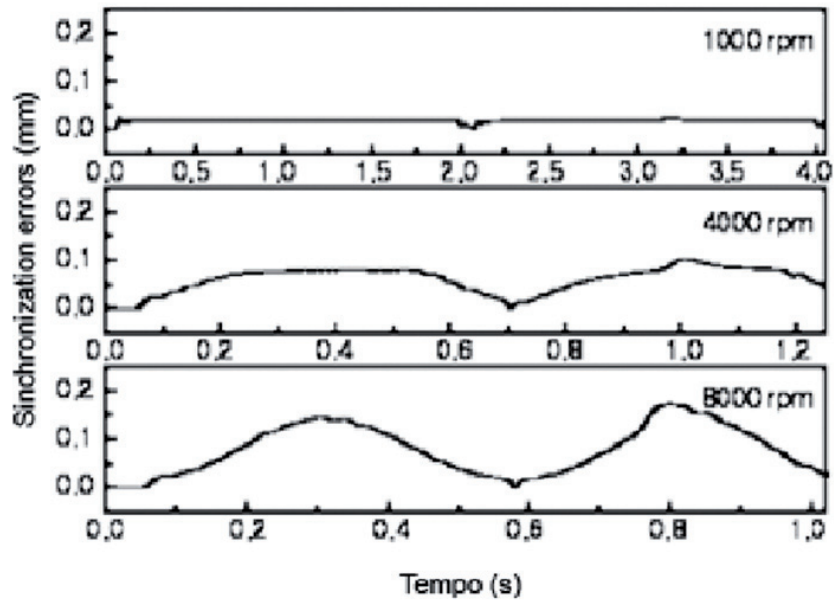

Fonte: Ahn et al. (2003)

É possível verificar no gráfico 5 a nítida influência do aumento dos erros de sincronismo com o aumento da velocidade de corte. Para rotações na faixa de $1000 \mathrm{rpm}$ os erros de sincronismo são de apenas alguns micrometros. Com o aumento das taxas de rotação para 4000 e $8000 \mathrm{rpm}$ há a presença de erros de sincronização acentuados entre 79 e $141 \mu \mathrm{m}$ (AHN et al., 2003). Outro parâmetro que influencia nos níveis de torque no rosqueamento é a profundidade de corte. O gráfico 6 demonstra as linhas de torque para os diâmetros acima, em conformidade e abaixo dos valores pré-estabelecidos.

Gráfico 6: Efeito da profundidade de corte sobre o torque

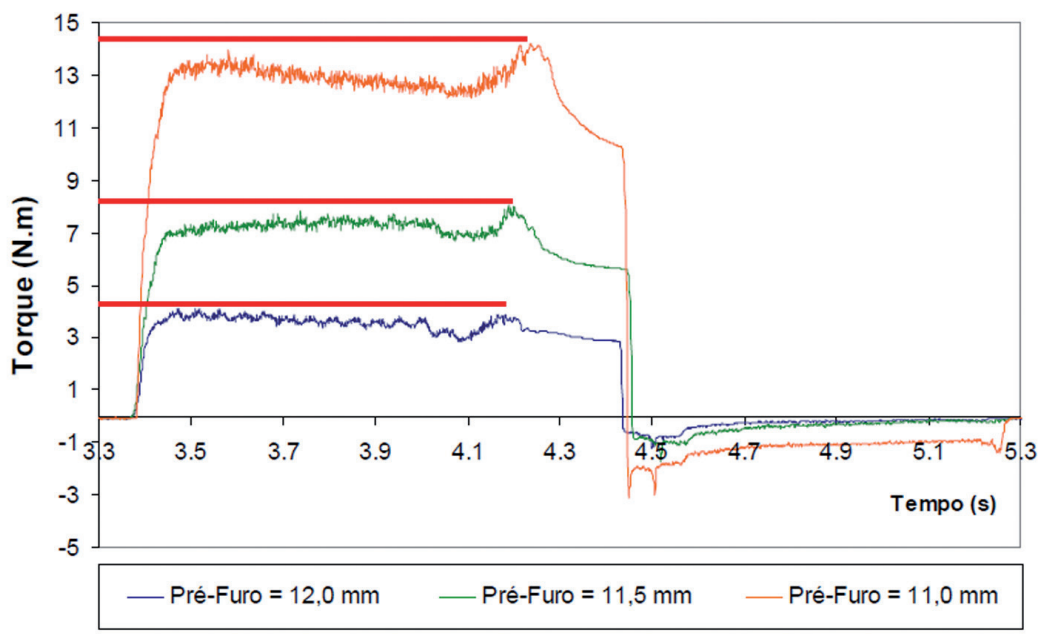

Fonte: Da Mota (2009) 
Segundo Da Mota (2009) o aumento progressivo do torque, observado no gráfico 6, se deve ao aumento das taxas de remoção e do aumento da área de contato entre os filetes da peça e da ferramenta. É importante atentar que a determinação do pré-furo deve satisfazer primeiramente a geometria dos filetes como recomendam as normas. A visualização dos dados de esforço axial no rosqueamento por corte é uma tarefa de grande complexidade. Pereira (2010) atribui este fenômeno à presença de cavaco e principalmente à falta de sincronismo da máquina ferramenta. $\mathrm{O}$ autor exemplifica sua afirmação expondo que no movimento de repouso da ferramenta no final da rosca, por exemplo, as variações apresentadas podem ser causadas por ajustes de posicionamento do eixo $Z$ ocasionados pela falta de sincronismo levando a uma leve compressão da ferramenta contra o filete já cortado.

O mesmo ocorre no movimento de retorno, pois com o aumento da velocidade de corte há um sensível aumento do esforço axial - superior, em alguns casos, aos níveis no movimento de entrada. Para simular a variação da força axial na falta de sincronismo, Pereira (2010) testou valores errôneos de passo, de modo que os resultados são mostrados no gráfico 7.

Gráfico 7: Valores de esforço axial para as diferentes faixas de passo programado

Passo 0,992
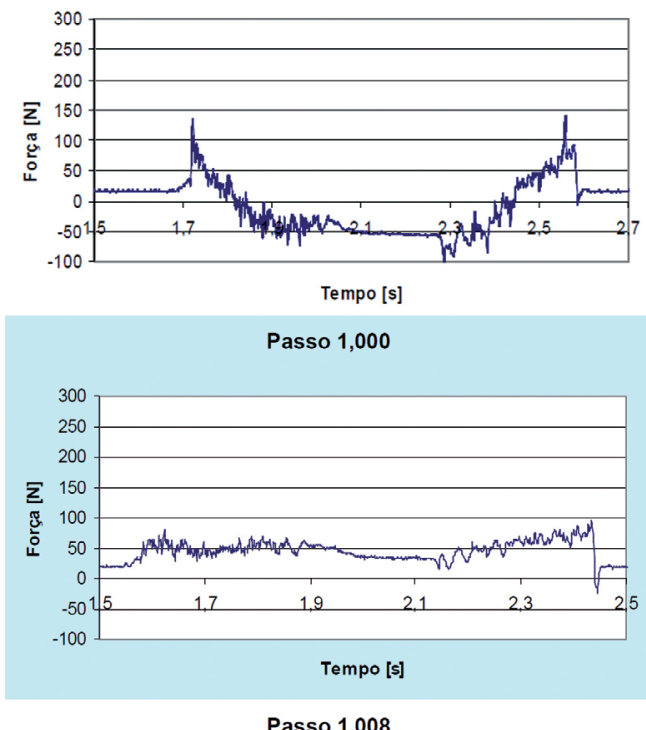

Passo 1,008

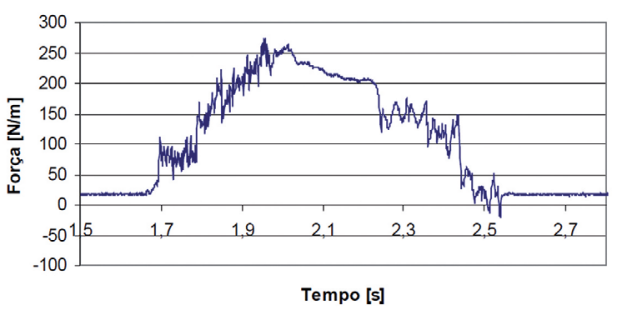

Fonte: Pereira (2010) 
Os valores obtidos no gráfico 7 são resultados do encontro entre os filetes da ferramenta e da peça, de modo que esta interação tende a "empurrar" o macho no sentido do spindle ou deslocá-lo em sentido a peça. Nota-se que há faixas onde o esforço é próximo ou igual a zero, inclusive com avanço diferente do recomendado. Este fenômeno está relacionado à força no sentido axial desenvolvida pelos filetes já formados sobre os filetes da ferramenta. É possível avaliar, portanto que é de grande importância a rigidez da fixação da ferramenta e da peça durante o processo.

\subsection{Grandezas físicas no processo de rosqueamento por laminação}

Apesar de ser uma tecnologia existente há algumas décadas, poucos são os estudos feitos para ampliar a compreensão dos fenômenos deste processo de rosqueamento. Dentre as vantagens de sua aplicação estão: a ausência de cavaco, acréscimo da vida da ferramenta, elevada velocidade de laminação e melhor resistência mecânica e qualidade dos filetes (FROMENTIN, 2004; ECKHARDT, 2003; IVANOV; KIROV, 1996). Porém a relação custo/beneficio ainda é um entrave para seu desenvolvimento em novas aplicações. Além disso, há limitações de processo que são referentes a aplicabilidade em materiais com baixo coeficiente de alongamento (menor que 10\%), exatidão no diâmetro do préfuro, valores de torque relativamente elevados e necessidade de excelente lubrificação da ferramenta durante o processo devido aos altos níveis de atrito. Desta forma é importante caracterizar as grandezas físicas e a sua relação com os parâmetros de processo. Modelos para predição dessas grandezas têm sido realizados ao longo das ultimas décadas para avaliação do torque e das forças axiais, como o trabalho de Chowdhary et al. (1997), porém grande parte de material que aborda o tema se baseia na experimentação científica, já que as interações neste processo possuem uma alta gama de variações inerentes às inúmeras variáveis.

O torque no processo de rosqueamento está ligado diretamente ao contato entre a peça e a ferramenta, sendo fator preponderante para a avaliação da capacidade de execução do processo, bem como as características mecânicas da ferramenta e dos sistemas de fixação da peça e da ferramenta, o gráfico 8 (a) ilustra uma configuração típica de torque no rosqueamento por laminação. 
Gráfico 8: Curva de torque no rosqueamento interno com macho laminador: a) Operação completa, b) fase de laminação efetiva
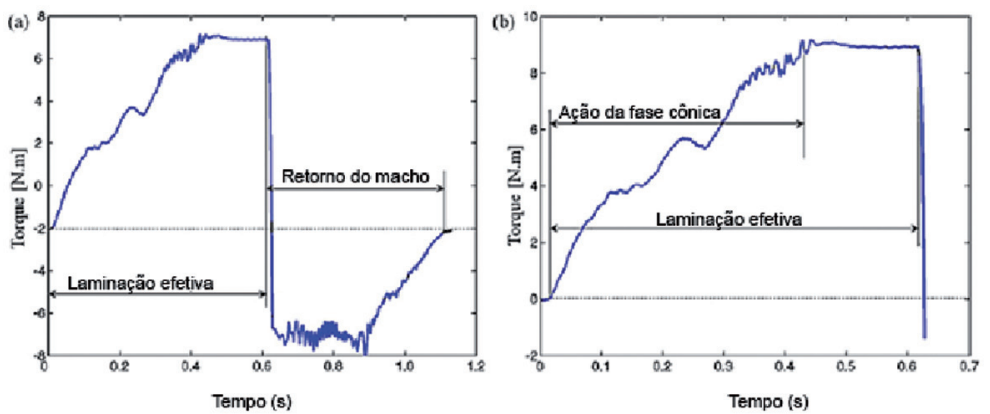

Fonte: Carvalho et al. (2012)

Verifica-se no (Gráfico 8 - a) a presença de três etapas principais, onde há diferentes níveis de torque em função das variáveis de cada etapa. Na primeira fase (Gráfico 8 - b), que se estende até 0,4 segundos aproximadamente, os níveis de torque aumentam de forma progressiva devido à penetração da fase cônica da ferramenta na peça executando a laminação parcial nos filetes. A partir deste ponto, até aproximadamente 0,6 segundos, os níveis se estabilizam a valores próximos ao máximo, devido ao aumento de atrito pela maior interação entre peça e ferramenta e principalmente pelo retorno elástico do material sobre a ferramenta e a ação da parte cilíndrica do macho sobre peça (Fromentin, 2004; CARVALHO et al., 2012). Desta etapa em diante os valores são consequência direta do atrito e da recuperação elástica do material escoado, desta forma a redução dos níveis de atrito se torna fator preponderante para o aumento da vida da ferramenta e consequentemente a estabilidade do processo.

Todavia, o controle dos níveis de atrito é efetuado com a utilização de meios lubrificantes, assim a caracterização destes agentes de redução de atrito deve ser bem entendida neste processo. É visto que utilização de emulsão é praticamente ineficaz para a redução dos valores de torque. O gráfico 9 demonstra a inferioridade da lubrificação da emulsão, tendo em vista que o poder de lubrificação da água é mínimo (FROMENTIN, 2004). É importante salientar que a viscosidade dos óleos utilizados também obteve pouca influência no processo ensaiado, levando a crer que as interações químicas influenciam fortemente este processo. 
Gráfico 9: Curva de torque no estágio de laminação comparando óleos com diferentes viscosidades

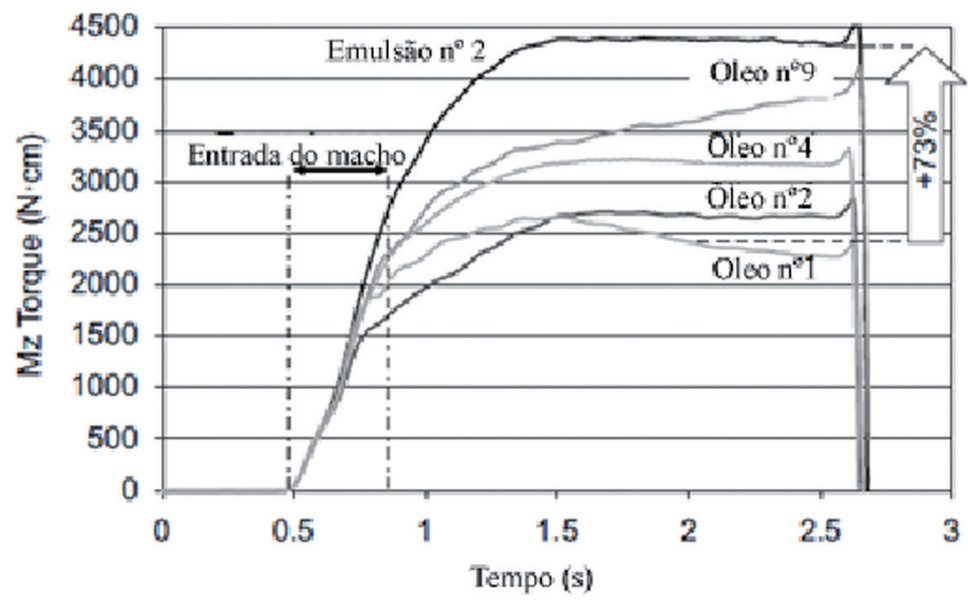

Fonte: Adaptado de Fromentin (2004)

Observa-se no gráfico 9 o efeito insignificante nos valores de torque com o uso de emulsão, ao passo que alguns óleos possuem mais e menos influência no que diz respeito à diminuição do torque. Óleos se mostram mais eficientes principalmente à, base de enxofre, sendo que quanto maior a concentração deste elemento melhor o desempenho do óleo (FROMENTIN, 2004). Outra meio de atenuar o efeito do atrito no torque destas ferramentas é a aplicação de finas camadas de revestimento. Porém como a tribologia deste processo é complexa, o efeito da aplicação de revestimento muitas vezes pode aumentar os valores de torque. O gráfico 10 mostra os valores testados por Fromentin com ferramentas de HSS com diferentes revestimentos e sem revestimento.

Gráfico 10: Efeito dos diferentes revestimentos nas curvas de torque na etapa de laminação

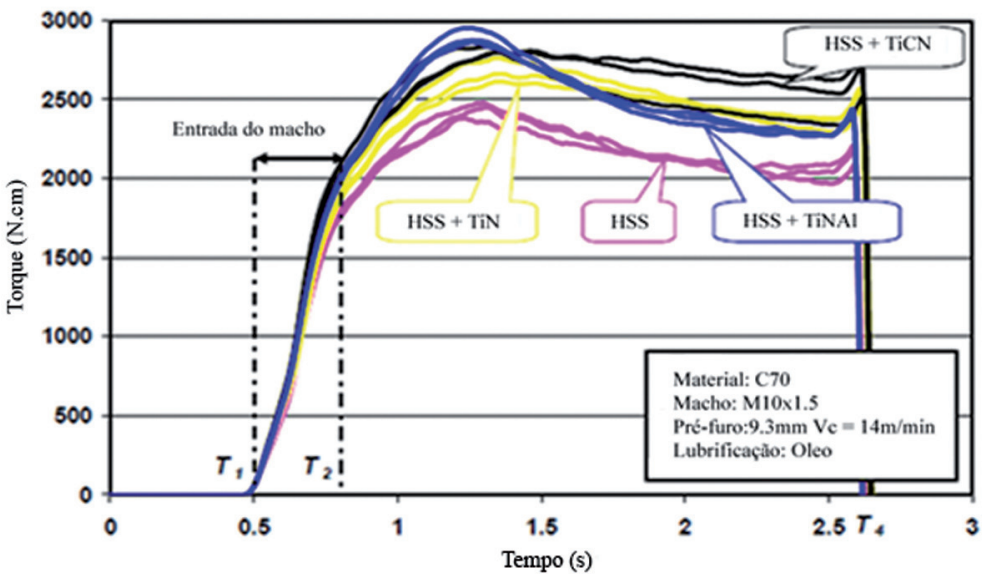

Fonte: Adaptado de Fromentin (2004) 
O gráfico 10 permite observar que com a adição de revestimento os níveis de torque tendem a aumentar, tanto na zona de entrada quanto na região cilíndrica da ferramenta. Fromentin (2004) explica que o aumento do torque com o uso de revestimento está ligado a presença do revestimento entre os filetes da ferramenta e da peça. Desta forma, o revestimento indicado para este processo deve ter ótimos níveis de adesão com o substrato como é o caso do TiAIN. Observa-se no gráfico 10 que na fase onde há grandes níveis de atrito entre os filetes, este revestimento é o que melhor se comporta. Todavia é importante salientar que a deposição de revestimento é de grande importância para o aumento da vida da ferramenta diminuindo as taxas de desgaste abrasivo (FROMENTIN, 2004). Outro fator que influencia grandemente os níveis de torque é o diâmetro do préfuro onde serão executadas as rosca. Quanto maior a relação diâmetro pré-furo/diâmetro da rosca, menores serão os valores de torque (CARVALHO et al., 2012). Entretanto o dimensionamento do pré-furo deve obedecer à melhor configuração de preenchimento dos filetes, o que pode variar de material para material.

Além do torque a força axial desenvolvida na ferramenta é importante para o entendimento do processo. O gráfico 11 ilustra o comportamento da curva da força axial durante o rosqueamento por laminação.

\section{Gráfico 11: Níveis de força axial durante as etapas do rosqueamento por laminação}

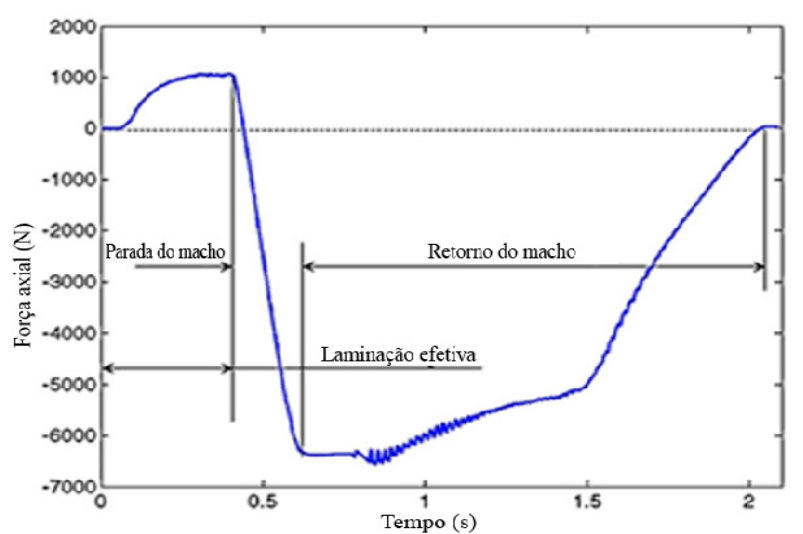

Fonte: Carvalho et al. (2012)

Pode ser observado no gráfico 11 que a primeira etapa do processo ocorre com a força de formação com aumento linear devido à ação da fase cônica dos filetes da ferramenta e logo após constituição dos filetes de rosca onde há ação dos filetes da parte cilíndrica do macho. Posteriormente há a etapa de parada da ferramenta no interior do furo seguido do seu retorno. Os valores de esforço são elevados devido principalmente à recuperação elástica do material que tende a comprimir os filetes da peça contra os da ferramenta (CARVALHO et al., 2012). Os valores de esforço podem ser afetados por diferenças entre o passo da rosca e o passo executado pela máquina-ferramenta, como 
pode ser observado no gráfico 12. Esta situação pode ocorrer por programação errônea do passo ou erro no sincronismo da máquina.

Gráfico 12: Curvas de torque e esforço axial a diferentes passos programados

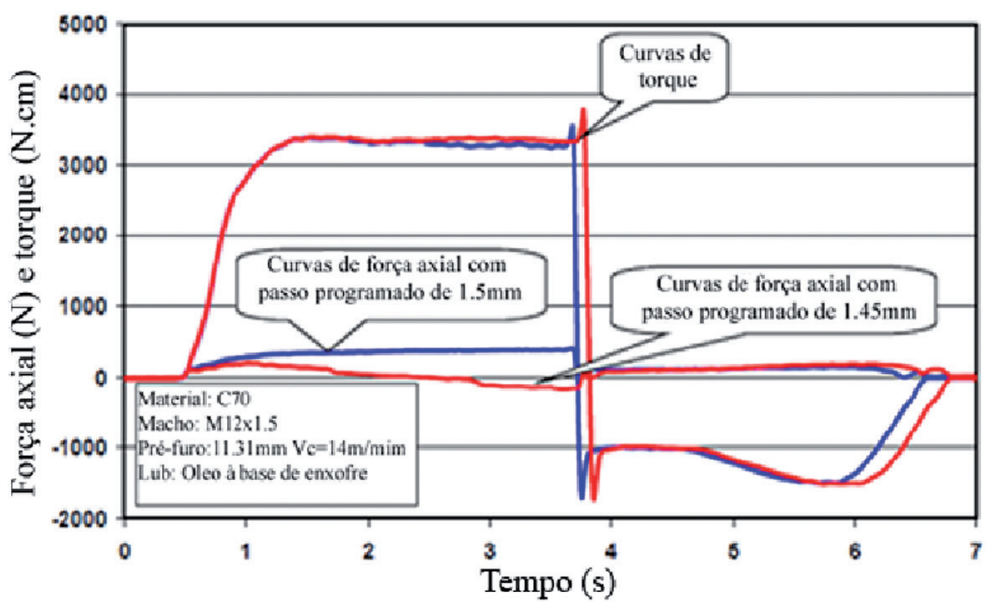

Fonte: Fromentin (2004)

O gráfico 12 apresenta as curvas de esforço axial para passos programados diferentes do recomendado. O erro intencional fora promovido para simular uma possível falta de sincronismo da máquina ferramenta durante o processo. No caso do passo programado a 1,45mm as curvas de esforço axial foram menores do que no caso do passo correto. Uma solução para diminuir as faixas de esforço axial sem comprometer a geometria da rosca é utilizando a fixação semi-rígida da ferramenta. Neste tipo de fixação, um sistema com molas evita que a ferramenta se mantenha axialmente rígida durante o processo de rosqueamento, de forma que os erros de sincronismo entre a máquina e a ferramenta pouco afetarão os valores de esforço axial e torque. Porém a utilização desses acessórios se mostra pouco produtiva e com valor de aquisição relativamente alto (DA MOTA, 2009). O gráfico 13 mostra os valores de torque e esforço axial com diferentes fixações e passos programados. 
Gráfico 13: Curvas de torque e esforço axial a diferentes passos programados e com diferentes fixações

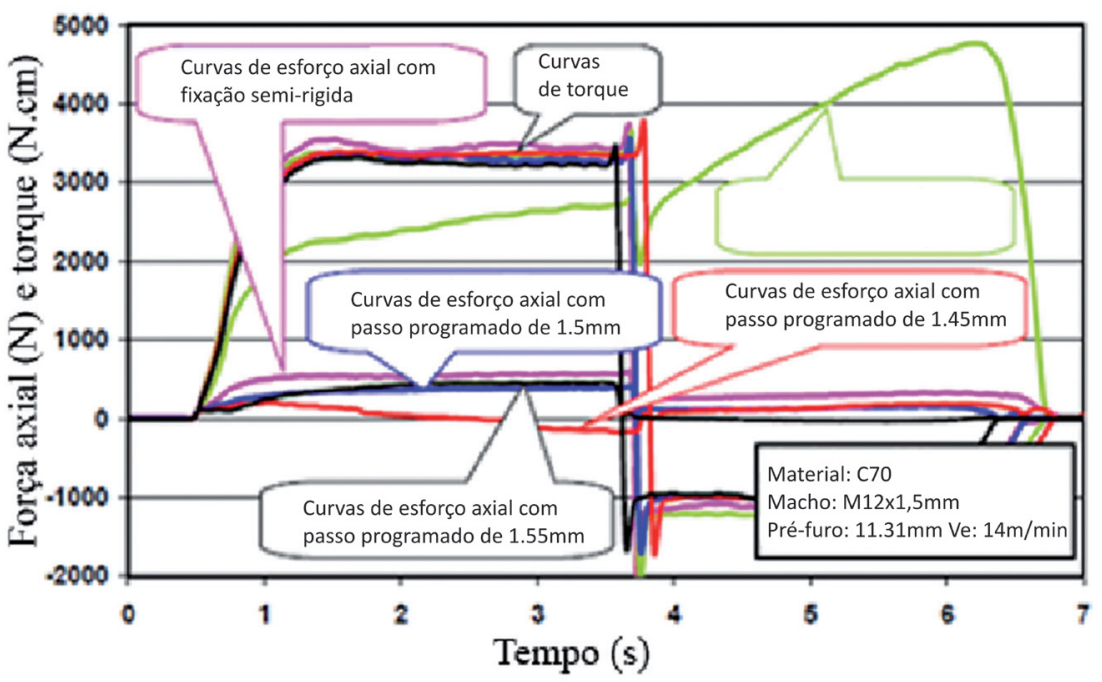

Fonte: Adaptado de Fromentin (2004)

Observa-se, no gráfico 13, que apenas as curvas de esforço axial apresentam níveis significativos de mudança com a variação do passo de modo que os níveis de torque permanecem similares. Isto ocorre porque a diferença no passo ocasiona maior ou menor avanço na ferramenta empurrando-a contra os filetes da rosca no sentido axial. As diferenças de torque sentidas são frutos da elevação do atrito ocasionados por este contato. Entretanto, há uma nítida diferença entre o esforço axial com fixação rígida e os valores com fixação semi-rígida no avanço e principalmente no retorno da ferramenta evidenciando o efeito dos erros de sincronismo durante o processo. Analogamente aos níveis de torque quanto maior a relação pré-furo/diâmetro da rosca menores serão os valores de força axial (CARVALHO et al., 2012).

Através do exposto anteriormente é possível inferir a aplicabilidade destes diferentes processos de rosqueamento interno em ADI. A tabela 2 ilustra a aplicação dos dois processos neste material.

Tabela 2: Comparação do processo de rosqueamento interno por corte e laminação

\begin{tabular}{l|l|l}
\hline Características & Corte & Laminação \\
\hline Presença do cavaco & Sim & Não \\
\hline Níveis de torque & Baixos & Elevados \\
\hline Confiabilidade no processo & Razoável & Boa \\
\hline
\end{tabular}




\begin{tabular}{l|l|l}
\hline Características & Corte & Laminação \\
\hline Durabilidade da vida da ferramenta & Razoável & Boa \\
\hline Precisão do diâmetro de pré-furo & Baixa & Alta \\
\hline Importância da lubrificação & Média & Alta \\
\hline Aplicação em materiais endurecidos & Razoável & Ruim \\
\hline Qualidade da geometria dos filetes & Razoável & Boa \\
\hline Resistência mecânica dos filetes & Razoável & Boa \\
\hline Velocidade de corte/laminação & Baixa & Elevada \\
\hline Rigidez da ferramenta & Baixa & Elevada \\
\hline Qualidade da superfície dos filetes & Razoável & Boa \\
\hline Dureza dos filetes & Razoável & Boa \\
\hline
\end{tabular}

Fonte: Dos autores (2012)

É possível observar através da tabela 2 a superioridade em relação à estabilidade do processo de rosqueamento por laminação, devido a ausência de cavaco na interface do processo, a qualidade geométrica e mecânica dos filetes produzidos e a rigidez da ferramenta. Entretanto é importante observar alguns cuidados em relação à aplicação em materiais com elevada dureza e baixo alongamento. As faixas toleráveis de dureza e coeficiente de alongamento para esta aplicação são de no máximo $300 \mathrm{HB}$ e no mínimo 10\%, respectivamente (FROMENTIN, 2004; DA MOTA, 2009). Cuidados com o processo também dever ser tomados para o melhor desempenho destas ferramentas, tais como, controle eficiente da lubrificação, precisão do pré-furo e rigidez do sistema de fixação da ferramenta devido aos níveis de torque presentes no processo. Desta forma as limitações de aplicação do processo de rosqueamento por laminação em ADI se referem à elevada dureza deste material e ao seu coeficiente de alongamento. Muitas das classes de ADI não possuem características aplicáveis a este processo. Porém para classes de resistência mecânica mais baixa a sua aplicação é recomendável à medida que se tem o aumento da confiabilidade. Devido à sua baixa usinabilidade o processo de usinagem acaba sendo feito antes do tratamento térmico, requerendo um reprocesso de acabamento para garantia das dimensões que porventura venham a ser afetadas pelas interações físicas. Desta forma o estudo de meios que viabilizem a usinagem de peças já tratadas é de grande importância. Quando se trata de rosqueamento esse fator se torna preponderante, pois mesmo que usinada antes do tratamento, a peça sofrerá deformações que comprometem a geometria das roscas, sendo necessário um reprocesso oneroso e arriscado que pode inutilizar um grande fluxo de processo. Depois de tratada esta peça apresenta características mecânicas que podem comprometer a aplicação de machos de corte devido aos altos níveis de abrasividade e formação de desgaste de flanco e cratera (GUESSER, 2009). Para sua aplicação prática é necessário a execução de ensaios de rosqueamento por laminação e corte com características como: boa fixação do conjunto máquina-ferramenta, máquina com ciclo de rosqueamento de alto desempenho e excelente lubrificação da ferramenta durante o processo. 


\section{CONCLUSÃO}

Tendo em vista a crescente demanda pela utilização de materiais que contribuam para a eficiência energética do produto final, a utilização de ADI vem cada vez mais sendo aumentada em peças de engenharia, principalmente na indústria automotiva. No entanto as propriedades mecânicas desse material podem gerar um fluxo de processo demasiadamente lento, tendo em vista a rapidez exigida para fabricação de peças seriada. Desta forma são necessárias medidas que visem sua usinagem depois do processo de tratamento térmico onde, contudo, suas propriedades mecânicas são um fator crítico. Sendo um processo complexo o rosqueamento merece atenção devido à sua característica de ser uma das ultimas operações de usinagem de uma peça, portanto é de suma importância a sua análise. Pode-se observar que as grandezas físicas que mais influenciam no processo de rosqueamento com macho de corte e laminação são o torque e o esforço axial. Para ambos os processos os níveis de torque estão relacionados ao desgaste da ferramenta, atrito e a profundidade de corte. Níveis elevados de torque podem levar a ferramenta à quebra e consequentemente o descarte de uma peça com alto valor agregado. Níveis elevados de esforço axial diminuem sensivelmente a vida da ferramenta e prejudicam a calibração da rosca produzida. Para a correta aplicação em ADI deve-se atentar aos valores de alongamento para cerca de no mínimo $10 \%$ e dureza no máximo à $300 \mathrm{HB}$. 


\title{
COMPARATIVE STUDY OF PROCESS OF INTERNAL THREAD WITH CUTTING AND FORMING TAP IN AUSTEMPERED DUCTILE IRON - AN APPROACH OF PHYSICAL QUANTITIES.
}

\begin{abstract}
This study aims to compare the performance of cutting taps and forming taps in the process of internal threading in austempered ductile iron (ADI), in view of the physical quantities involved. A large majority of the parts used in the industry has internal threads to be used as fastening element and transmission of movement. However many of these parts are made of relatively hard machining material, as is the case of ADI. Achieving stability and reliability in the process is of paramount importance when dealing with internal threading, as it can compromise the entire previous process flow, should it fail. A survey of the state of the art showed the need to characterize and measure the phenomena related to process variables as well as the physical characteristics of the tool and of the workpiece so as to provide the best possible way to its applicability. The study points to a theoretical superiority of the process of threading by rolling, rather than by the similar process of cutting in ADI. This statement is based on the best characteristics of these tools for this process, such as higher torque strength, for example. In contrast it revealed the criticality of this application due to the high hardness and abrasion characteristics of ADI, besides the need for a good fixation and stability of the entire machine tool. However there is a need to develop tests that enable the visualization of parameters studied and characterization of the best process, in view of the large number of variables involved.
\end{abstract}

Keywords: Threading. ADI. Forming.

\section{REFERÊNCIAS}

AHN, J. H. et al. Effects of Synchronizing Errors on Cutting Performance in the Ultra-Highspeed Tapping. CIRP Annals - manufacturing Technology, Coréia, vol. 52, issue 1, pp. 53-56, 2003.

BARBOSA, Patrícia Alves. Furação em ferros fundidos austemperados e nodular perlítico. 2009. 124 f. Dissertação (Mestrado em engenharia mecânica) - Universidade Federal de Uberlândia (UFU), Uberlândia, 2009.

CALLISTER JUNIOR, William D. Ciência e Engenharia de Materiais: uma Introdução. Rio de Janeiro: LTC, 2002.

CAO, Tengyun. SUTHERLAND, John W. Investigation of thread tapping load characteristics through mechanistics modeling and experimentation. International Journal of Machine Tools \& Manufacture, USA, vol. 42, no.14, pp.1527:1538, 2002. 
CARVALHO, Alessandra Olinda de et al. Analysis of form threads using fluteless taps in cast magnesium alloy (AM60). Journal of Materials Processing Technology, Brasil, vol.212, pp.1753-1760, 2012.

CHOWDHARY, Sammer et al. Modeling and analysis of internal thread forming. Urbana, Illinois, USA, 1997.

DA MOTA, Paulo Rosa. Investigação do comportamento de ferramentas de aço rápido no processo de rosqueamento interno em alta velocidade de corte. 2006. $142 \mathrm{f}$. Dissertação (Pós-graduação em engenharia mecânica) - Universidade Federal de Uberlândia (UFU), Uberlândia, 2006.

Estudo do processo de rosqueamento com macho de corte de metal duro em ferro fundido vermicular. 2009. 160 f. Tese (Doutorado em engenharia mecânica) Universidade Federal de Uberlândia (UFU), Uberlândia, 2009.

ECKHARDT, Moacir. Relação entre processo, microestrutura e propriedades mecânicas na furação por escoamento de aços de baixo carbono. 2003. $217 \mathrm{f}$. Tese (Doutorado em engenharia mecânica) - Universidade Federal de Santa Catarina (UFSC), Florianópolis, 2003.

FROMENTIN, Guillaume. Etude mecanique et technologique du taraudage par deformation: application aux aciers pretraits. 2004. $192 \mathrm{f}$. Tese (Doutorado em processos de fabricação) - L’EcoleNationaleSuperieure D’Arts Et Metiers, Paris-França, 2004.

GUESSER, Wilson Luiz. Propriedades mecânicas dos ferros fundidos. São Paulo: Blucher, 2009.

IVANOV, Veliko; KIROV, Vanio. Rolling of internal threads: Part 1. Rouse, BU, 1996.

KEOUGH, John R. Austempered Ductile Iron (ADI): A Green Alternative for India. Michigan, USA, 2000.

KLOCKE, F. et al. Fundamental Wear Mechanisms when Machining Austempered Ductile Iron (ADI). CIRP Annals - Manufacturing Technology, Alemanha, vol.56, pp.73-76, 2007.

LORENZ G. On Tapping Torque and Tap Geometry. CIRP Annals - Manufacturing Technology, Austrália, vol. 29, pp.1-4, 1980.

PEREIRA, Igor Cezar, Analise do torque e da força axial, em diferentes condições de corte durante o rosqueamento de dois ferros fundidos cinzentos (CrCuSn e CrCuSnMo) e um ferro fundido vermicular da classe 350. 2010. 99 f. (Pós-graduação em engenharia mecânica) - Universidade Federal de Uberlândia (UFU), Uberlândia, 2010. 
REIS, Alexandre Martins et al. Estudo da relação entre o sinal de potencia e o desgaste da ferramenta para o processo de rosqueamento interno. In: POSMEC - Simpósio do programa de pós-graduação em engenharia mecânica, 13., 2003, Uberlândia/MG. Anais... Uberlândia, MG: Universidade Federal de Uberlândia/Faculdade de Engenharia Mecânica, 2003.

SEKER, Ulvi, HASIRCI, Hasan. Evaluation of machinability of austempered ductile irons in terms of cutting forces and surface quality. Journal of Materials Processing Technology, Turquia, vol. 173, pp.260-268, 2006.

VELDHUIS, S. C. DOSBAEVA, G. K. BENGA, G. Application of ultra-thin fluorine-content lubricating films to reduce tool/workpiece adhesive interaction during thread-cutting operations. International Journal of Machine Tools \& Manufacture, Canadá. vol. 47 issue 3-4, pp.521-528, mar., 2007.

\section{SOBRE OS AUTORES}

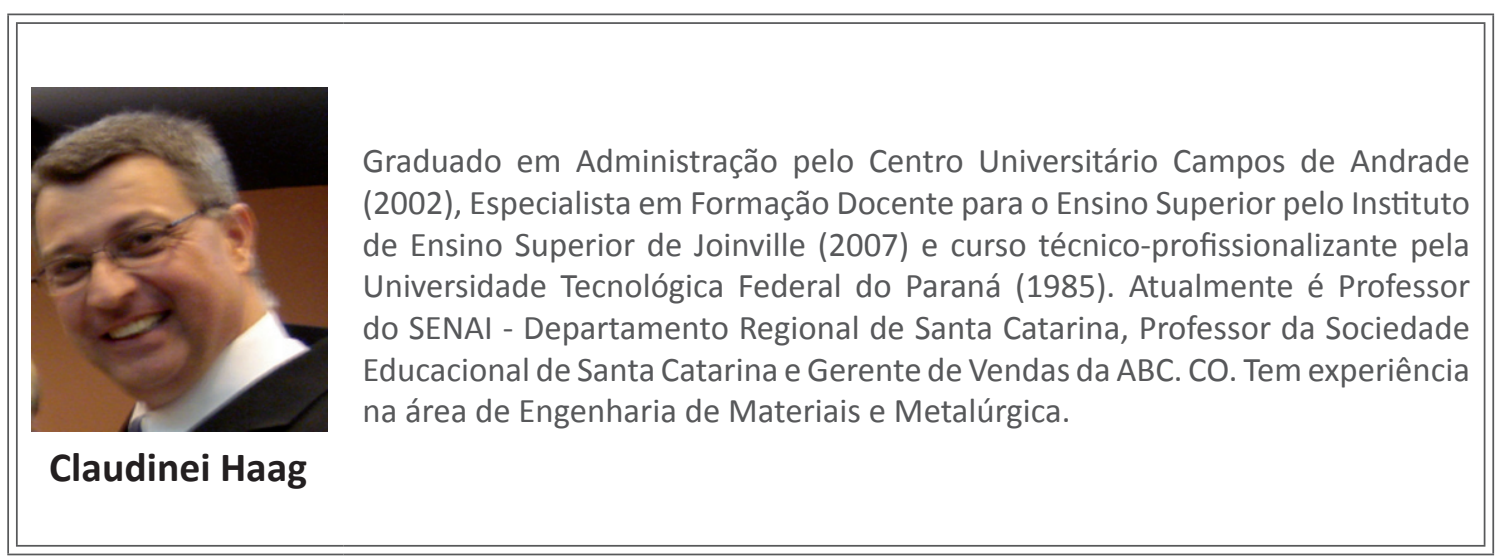

Graduado em Tecnologia em Fabricação Mecânica -Serviço Nacional de
Aprendizagem- SENAI /SC - Departamento Regional de Santa Catarina (2011).
Tem experiência na área de processo de fabricação, especificamente na área de
usinagem, com trabalhos voltados ao desenvolvimento e análise de processo
visando à melhoria contínua e atualização tecnológica, atualmente, atua na
área de gerenciamento de ferramentas de corte em empresa do setor metal
mecânico do sul do país.
Marcos Roberto
Morachik

